RESEARCH NOTE

\title{
THE OCCURRENCE OF THE AVIAN SCHISTOSOME ALLOBILHARZIA VISCERALIS KOLÁŘOVÁ, RUDOLFOVÁ, HAMPL ET SKÍRNISSON, 2006 (SCHISTOSOMATIDAE) IN THE TUNDRA SWAN, CYGNUS COLUMBIANUS (ANATIDAE), FROM NORTH AMERICA
}

\author{
Sara V. Brant \\ Center for Evolutionary and Theoretical Immunology, Department of Biology, University of New Mexico, Albuquerque, New \\ Mexico 87110, USA
}

\begin{abstract}
Twelve tundra swans, Cygnus columbianus (Ord), from Nevada and one from New Mexico were collected and examined for schistosomes. Mature worms, determined as Allobilharzia visceralis, were found in $92 \%$ of the swans, in the inferior mesenteric vein of the large intestine and its branches. In 12 cases, there was endophlebitis of the inferior mesenteric vein. The morphology of the worms is consistent with the recently described genus Allobilharzia. Placement in this genus was confirmed also by phylogenetic analysis of nuclear $28 \mathrm{~S}, 18 \mathrm{~S}$ and, internal transcribed spacer (ITS) ribosomal DNA (rDNA), and mitochondrial cytochrome oxidase I (CO1) sequences. Data further suggest the worms are conspecific with the European $A$. visceralis, the only described species of the genus and which was found to be the sister taxon to the most diverse avian schistosome genus, Trichobilharzia. This is the first report of a schistosome infection from native swans in North America.
\end{abstract}

Schistosomes have achieved notoriety because they are the etiological agent of the human disease, schistosomiasis, which is caused by 7 of 21 nominal species of Schistosoma; namely S. japonicum, S. malayensis, S mekongi, S. mansoni, S. mattheei, S. intercalatum, S. haematobium, and S. guineensis (see Webster et al. 2006). Although mammalian schistosomes are better known for this reason, avian schistosomes by comparison are much more diverse and widespread (Horák et al. 2002, Brant et al. 2006). For example, Trichobilharzia is the most speciose of the 14 named schistosome genera, with roughly 40 species described, all from birds (Blair and Islam 1983, Horák et al. 2002). Cercariae of Trichobilharzia play a significant role in outbreaks of cercarial dermatitis (swimmer's itch) in humans across the world, though there are several other schistosome genera that also cause dermatitis (Cort 1950, Jarcho and van Burkalow 1952, Leedom and Short 1981). Recently, investigations of an outbreak of cercarial dermatitis in Iceland led to the discovery of a new genus and species of schistosome, Allobilharzia visceralis Kolářová, Rudolfová, Hampl et Skírnisson, 2006, in Cygnus cygnus whooper swans. This new finding inspired the current study, wherein I examined a swan species native to North America, the tundra swan, Cygnus columbianus columbianus (Ord, 1815).

Twelve (5 young of the year) tundra swans, C. c. columbianus, were collected during the hunting season from Stillwater National Wildlife Refuge, Churchill County, Nevada $\left(39^{\circ} 54^{\prime} \mathrm{N}, 118^{\circ} 49^{\prime} \mathrm{W}\right)$ on $18-19$ November 2005 . One young of the year was collected in January 2006 from Lake Avalon,

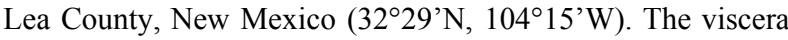
and nasal tissues were examined for schistosomes between 30

Address for correspondence: S. Brant, University of New Mexico, Department of Biology, 167 Castetter Hall, Albuquerque, New Mexico 87110, USA. Phone: ++1 505277 2517; Fax: ++1 505277 0304; E-mail: sbrant@unm.edu

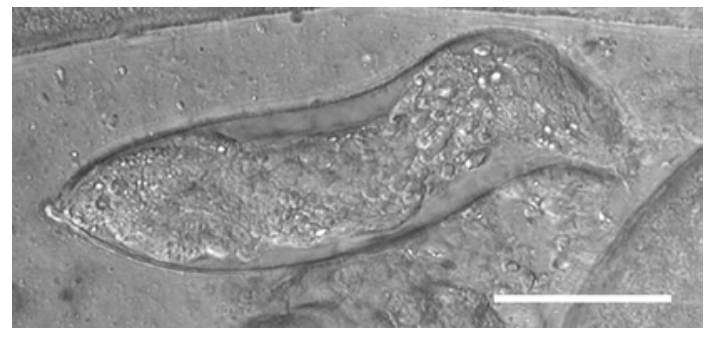

Fig. 1. Egg of Allobilharzia visceralis in Cygnus columbianus from a mass of adults and tissue in the nodule above the inferior mesenteric vein (see Fig. 3). Scale bar $=50 \mu \mathrm{m}$.

minutes to 6 hours after death, except for the specimen from New Mexico which was previously frozen. Intestinal scrapings and samples from the enlarged large inferior mesenteric vein were examined for eggs, intestinal lesions were photographed, and then worms were teased out and either relaxed and killed in hot water or put into $95 \%$ ethanol for subsequent DNA analysis. Attempts were made to hatch eggs. Faeces were rinsed, and then diluted in store bought spring water in an Erlenmeyer flask. The flask was $90 \%$ covered from the bottom up, in aluminium foil to expose to light only the top 3 $\mathrm{cm}$ of the flask. No miracidia were recovered. Specimens of Dendritobilharzia pulverulenta were collected from Mergus merganser (Cheboygan County, Michigan, August 2005) and Gigantobilharzia huronensis was collected from Agelaius phoeniceus (Albuquerque, Bernalillo County, New Mexico, 1998).

Worms were stained in Semichon's acetocarmine and mounted in Canada balsam on slides for measurements and morphology (Pritchard and Kruse 1982). Voucher specimens of Allobilharzia were deposited in the U.S. National Parasite Collection, Beltsville, Maryland (USNPC\# 099527).

DNA was extracted from fixed whole worms with the DNeasy Tissue Kit (Qiagen, Valencia, CA, USA) according to manufacturer's guidelines. Fragments of DNA (internal transcribed spacer - ITS (18S partial sequence; ITS1, 5.8S, ITS2, and $28 \mathrm{~S}$ partial sequence), $18 \mathrm{~S}$ and $28 \mathrm{~S}$ rDNA, and mtDNA cytochrome oxidase 1 (CO1) were amplified by polymerase chain reaction (Takara Ex Taq kit, Takara Biomedicals, Otsu, Japan) and sequenced using previously published primers: ITS: its4, its5 (Dvořák et al. 2002), 3S (Bowles et al. 1995) and 4S (Bowles and McManus 1993), 18S, 28S, and CO1 primers as referenced in Morgan et al. (2003) and Snyder (2004). PCR products were purified with Montage Microcon

The information given in this paper was presented at the XI International Congress of Parasitology - ICOPA XI, held in Glasgow, UK, August 6-11, 2006. 

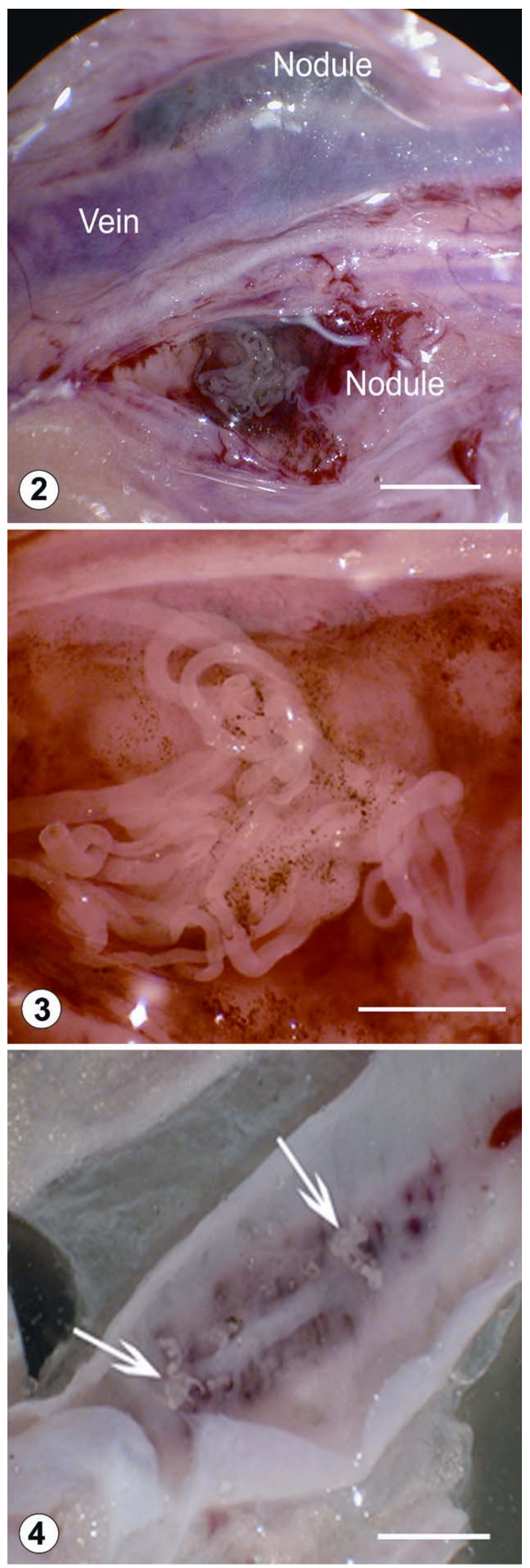

columns (Millipore, Billerica, MD, USA). Sequencing reactions were performed with Applied Biosystems BigDye direct sequencing kit, version 3.1 (Applied Biosystems, Foster City, CA, USA). The ITS, 18S, 28S, and CO1 gene regions were used to estimate the phylogenetic position of the specimens found in this study. The ITS region was used to compare with the Allobilharzia visceralis samples from Kolárová et al. (2006). Since there does not exist ITS sequence data for all known genera of the family, the $18 \mathrm{~S}, 28 \mathrm{~S}$, and CO1 sequence data were used to place the samples in this study within the larger context of the family Schistosomatidae (Brant and Loker 2005, Brant et al. 2006).

The ITS ( $857 \mathrm{bp}$ ) sequences generated by this study were the following: Allobilharzia visceralis (GenBank accession numbers EF071989-91), Dendritobilharzia pulverulenta (EF071988) and Gigantobilharzia huronensis (EF071986, EF071987). From GenBank the following accession numbers were available for ITS sequences for schistosomes: Trichobilharzia (AF263829, AY713969-73), Allobilharzia (DQ067561), Gigantobilharzia (AY713963), Dendritobilharzia (AY713962), and outgroups Schistosoma (Z21716-18, AY446080, AY197343). The sequences analysed were the same as used in Kolářová et al. (2006): part of ITS1, all of $5.8 \mathrm{~S}$ and ITS2 and part 28S. The $18 \mathrm{~S}(1,815 \mathrm{bp}), 28 \mathrm{~S}(3,829$ bp) and CO1 (711 bp) sequences new to this study were Allobilharzia visceralis (EF114219-24). The remaining taxon accession numbers can be found in Brant et al. (2006). Sequences were assembled and edited using Sequencher ver. 4.2 (Gene Codes, Ann Arbor, MI, USA), and subsequently aligned by eye in Se-Al (Rambaut A. 1996. Se-Al: Sequence Alignment Editor. http://evolve.zoo.ox.ac.uk). Positions for which alignment was uncertain were removed from the data set (alignments are available upon request).

Phylogenetic analyses using maximum parsimony (MP), maximum likelihood (ML) and minimum evolution (ME) were carried out using PAUP* ver. $4.0 \mathrm{~b} 10$ (Swofford 2002) and Bayesian inference using the program MrBayes 3.1 (Huelsenbeck and Ronquist 2001). Modeltest (Posada and Crandall 1998) was used to determine the best nucleotide substitution model for ML and ME analyses. For ITS, the model $\mathrm{TVM}+\mathrm{G}$ was selected. Gaps were treated as missing data information residues. For the combined gene tree, each gene was analysed independently and combined, and rooted with the spirorchiid outgroup. The GTR $+\mathrm{I}+\mathrm{G}$ model from Modeltest, based on A.I.C. criteria, was used for the combined dataset. Parsimony trees were reconstructed using heuristic searches (100 replicates), random taxon-input order and treebisection and reconnection (TBR) branch swapping. Optimal ME and ML trees were determined from heuristic searches (500 replicates for ME, 10 replicates for ML), random taxoninput order, and TBR. Nodal support was estimated by bootstrap (200 replicates) and was determined for the MP and ME trees using heuristic searches (10 replicates), each with random taxon-input order.

Figs. 2-4. Allobilharzia visceralis in the large intestine of Cygnus columbianus. Fig. 2. From the top: a nodule on the inferior mesenteric vein; below that, a nodule on a smaller vein cut open to show adult worms and egg-tissue debris (brown spots, see Fig. 3). Fig. 3. Close-up of worms in the nodule on the vein from Fig. 2. Fig. 4. The lumen of the inferior mesenteric vein; adult worms infiltrating through the dorsal side of the vein from the nodule (Fig. 2). Arrows highlight some of the worms. Scale bars: Fig. $2=1.4 \mathrm{~mm}$; Fig. $3=0.32$ $\mathrm{mm}$; Fig. $4=3 \mathrm{~mm}$. 
Table 1. Measurements of male and egg Allobilharzia visceralis from this paper compared to those of Kolářová et al. (2006). $\mathrm{n}=8$ except for total length where $\mathrm{n}=1$.

\begin{tabular}{llll}
\hline & Range $(\mu \mathrm{m})$ & Mean $\pm \mathrm{SD}(\mu \mathrm{m})$ & $\begin{array}{l}\text { Mean } \pm \mathrm{SD}(\mu \mathrm{m}) \\
\text { Kolářová et al. 2006 }\end{array}$ \\
\hline Total length & $65 \mathrm{~mm}$ & $77 \pm 2.1 \times 62 \pm 2.5$ & $57 \pm 14 \times 48 \pm 11$ \\
Oral sucker & $75-79 \times 60-65$ & $511 \pm 103.5$ & $361 \pm 77$ \\
Oral sucker to acetabulum & $410-730$ & $91 \pm 1.01$ & $107 \pm 41 \times 95 \pm 32$ \\
Acetabulum & $90-2$ & $1,005 \pm 276.6$ & \\
Acetabulum to gynecophoral canal & $700-1,520$ & $775 \pm 225.2$ & $831 \pm 132$ \\
Length gynecophoral canal & $350-1,001$ & & $>170$ \\
Number of testes & $>400$ & $164.6 \times 43.3$ & $132 \pm 10 \times 28 \pm 2$ \\
Immature eggs (from nodule mass) & $147-175.2 \times 40-47.7$ & & \\
\hline
\end{tabular}

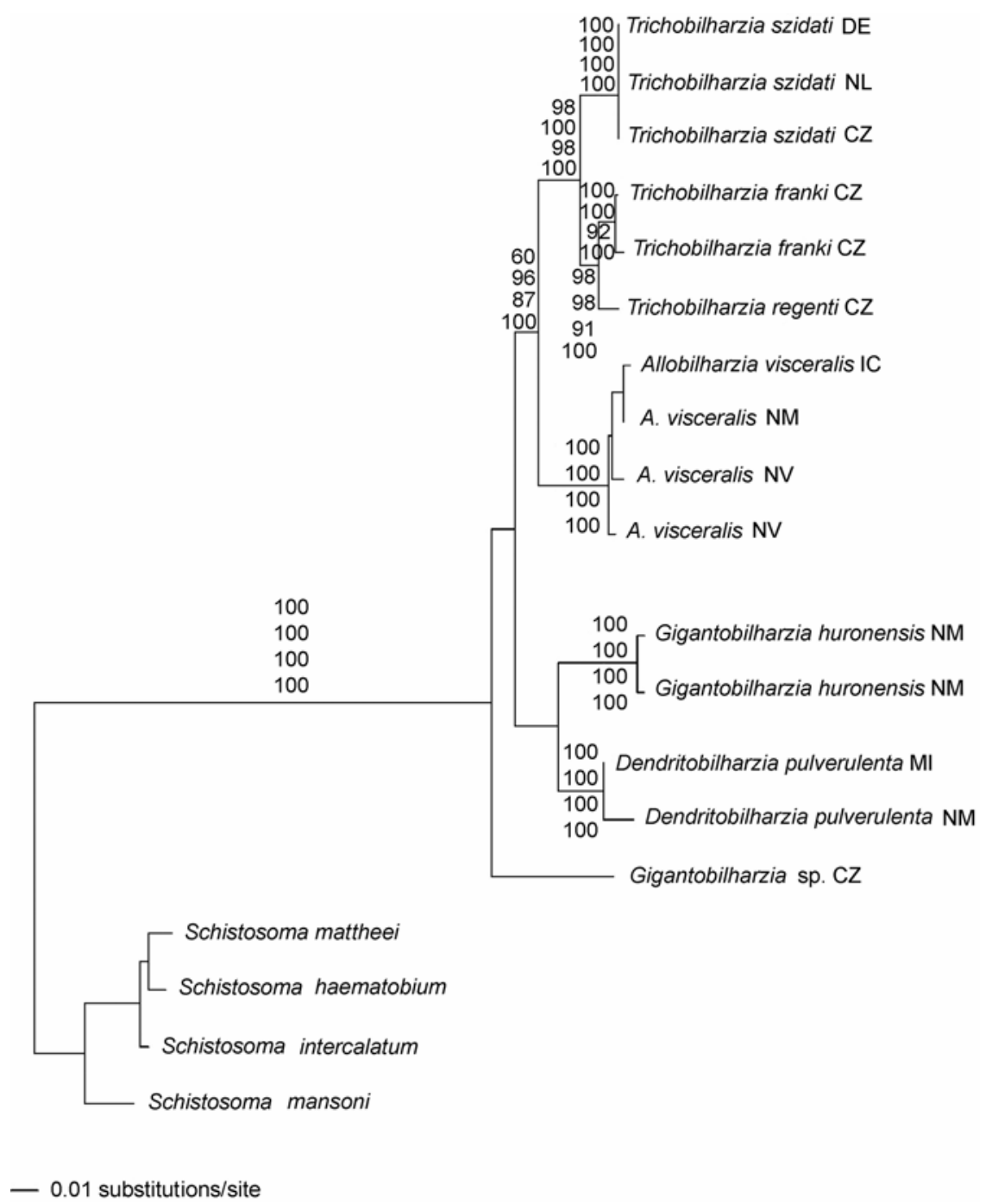

Fig. 5. Phylogenetic tree based on partial ITS region. Nodal support shown by bootstrap values for ME, MP, and ML and Bayesian posterior probabilities, respectively. The tree shown was constructed using ML. Taxon names are followed by their geographic locality (in Europe, $\mathrm{DE}=$ Germany, $\mathrm{NL}=$ Netherlands, $\mathrm{CZ}=$ Czech Republic, $\mathrm{IC}=$ Iceland; in the USA, NM = New Mexico, $\mathrm{NV}=$ Nevada, $\mathrm{MI}=$ Michigan) .

For the Bayesian analysis, there were five partitions in the data set $18 \mathrm{~S}, 28 \mathrm{~S}(\mathrm{Nst}=6$ rates $=$ gamma ngammacat $=4) \mathrm{CO} 1$ codon positions codon 1 , codon 2 , and codon 3 (Nst $=6$ ratesinvgamma ngammacat $=4$ ) followed by the following parameter settings: unlink shape $=($ all $)$ pinvar $=($ all $)$ statefreq $=($ all $)$ revmat $=$ all; preset ratepr $=$ variable. Four chains were run si- multaneously for $5 \times 10^{5}$ generations, trees sampled every 100 cycles, the first 2,000 trees with preasymptotic likelihood scores were discarded as burn-in, and the retained trees were used to generate $50 \%$ majority-rule consensus trees and posterior probabilities. 


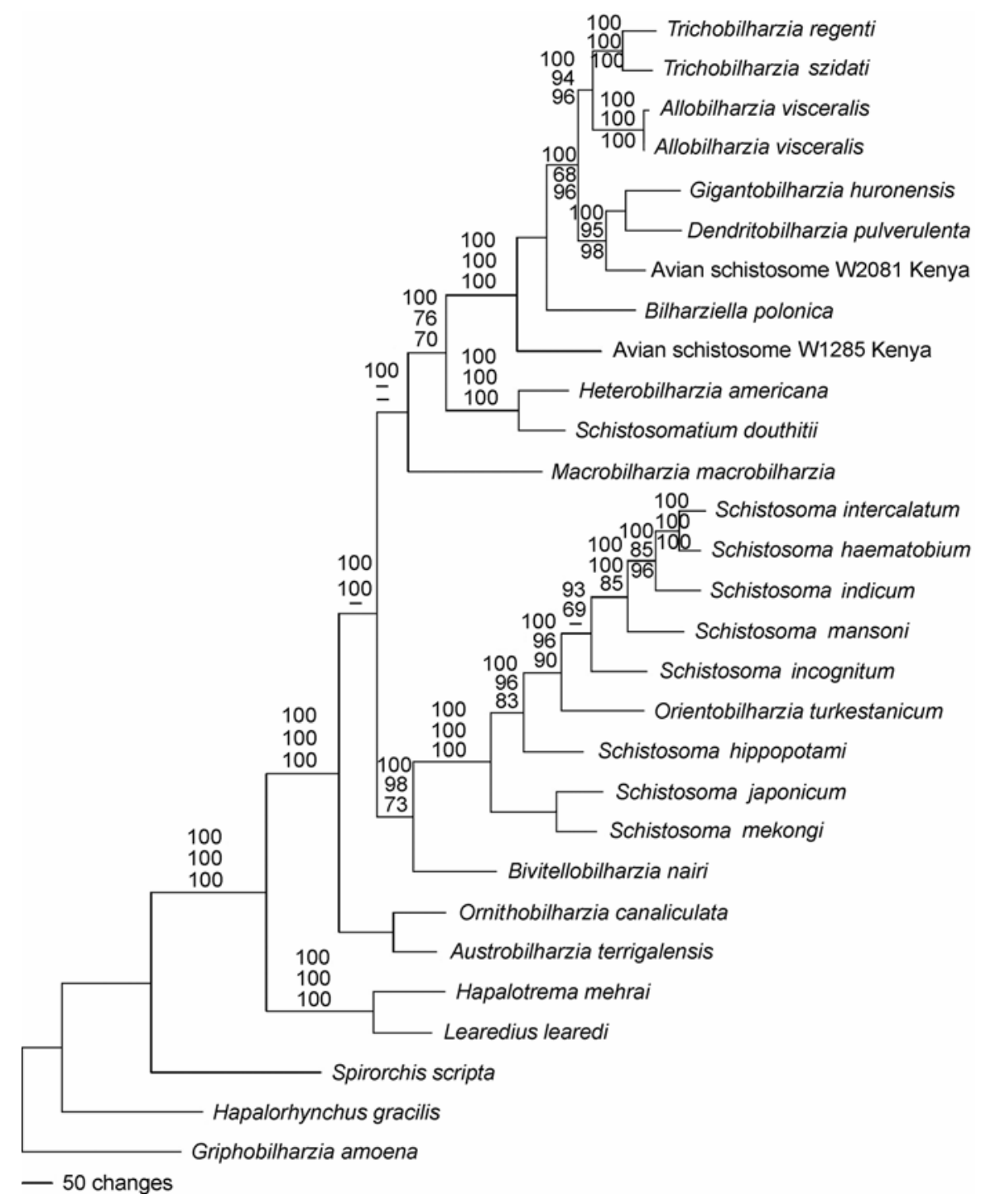

Fig. 6. Phylogenetic tree based on concatenated sequences of $18 \mathrm{~S}$ and $28 \mathrm{~S}$ rDNA and CO1 mtDNA regions. Nodal support shown by bootstrap values for Bayesian posterior probabilities, ME, and MP respectively.

Allobilharzia visceralis was recovered from 11 of the 12 $(92 \%)$ swans from Nevada and the one from New Mexico in the serosal and mesenteric veins of the large intestine of both juvenile and adult swans (Figs. 1-4). Species identification was based on both morphology and ITS gene sequence comparison to the worms from Iceland. This species was the only schistosome species recovered. No schistosomes were found in nasal tissue. Both the ITS phylogeny and the combined $18 \mathrm{~S}$ $28 \mathrm{~S}$ and $\mathrm{CO} 1$ phylogenetic analysis for this species of schistosome support it as a sister clade to the genus Trichobilharzia (Figs. 5, 6) and confirm the results of Kolářová et al. (2006). Analysis of the separate genes also recovered the similar topology with variation at the tips of the clades (data not shown). Measurements of females are not reported, as intact worms were not recovered. Measurements were made from fragments of eight males (total length based on one male) and were compared to those of Kolářová et al. (2006) in Table 1. The suckers, body and lining of gynecophoral canal have spines; oesophagus bifurcates just before the acetabulum, caecal reunion posterior to the gynecophoral canal but was seen in only two specimens. Posterior end of tail is spatulate.

This is the first report of schistosomes from C. c. columbianus. Prior to this study, there have been several reports of schistosomes in swans from Europe and Australia including the black swan, Cygnus atratus, in Australia (Johnston 1941), Cygnus olor, the mute swan, (Szidat 1939, van den Broek 1965, Palmer and Ossent 1984, Koláŕová et al. 2005) and Cygnus cygnus, the whooper swan, (Kolářová et al. 2005) in Europe. Most of the worms in those papers were classified as Trichobilharzia. However, it is not clear from these reports how the worms were identified, as they can be confused easily with other genera of avian schistosomes. Other species of schistosomes (mainly of Dendritobilharzia) have been implicated in causing the death of swans, such with the whooper swan (Levine et al. 1956, Wilson et al. 1982, Graczyk et al. 1993).

The gross pathology of infection seen in the adult and juvenile birds (Figs. 2-4) was similar to that reported in Kolářo- 
vá et al. (2006). However, unlike the swans discussed in the previous paper, the swans examined for this study were collected during the hunting season and appeared healthy. There were no granulomas in the liver of juvenile or adult birds and by gross examination they did not appear to suffer morbidity from this infection. Swans are not mature until about three to four years and the pathology, prevalence and intensity of the worms in the young of the year swans collected for this study appeared similar to the adult swans. Therefore, by breeding age these swans may have been infected for a minimum of three years. It is not known at this time if adults have acquired immunity and can become infected as adults (Ellis et al. 1975).

The morphological similarity and genetic divergence of the ITS $(0.2 \%)$ sequences of Allobilharzia generated in this study compared with the samples from Kolářová et al. (2006) strongly suggests that the worms recovered belong to the same species. Additionally, the similarity suggests that they share common transmission sites, one that must occur in the northern latitudes. Cygnus columbianus is comprised of two subspecies. The tundra swan, C. $c$ columbianus has a breeding range in the subarctic and arctic tundra of North America (Bellrose 1980, Kear 2005) and winters on the Pacific coast from Vancouver Island to central California, and inland, then Atlantic coast from New Jersey to South Carolina (Limpert et al. 1991). Bewick's swan, C. columbianus bewickii Yarrell, 1830, breeds only in arctic Russia and winters in eastern Asia and northern Europe. However both subspecies will occasionally cross the Bering Strait (Kear 2005). Additionally, the breeding ranges of Cygnus cygnus, C. buccinator, C. columbianus (both subspecies) and C. olor are holarctic circumpolar and thus range overlaps occur at the contact zones of these various species of swans, i.e. Siberia/Aleutian Islands of Alaska, USA (Evans and Sladen 1980, Kondratyev 1991). In fact, the whooper swan, C. cygnus, is a rare visitor to Alaska and the tundra swan is a rare visitor to Siberia; the breeding distribution of the whooper swan is subarctic Eurasia and in some cases does overlap with some Asian stragglers of the tundra swan. In a recent study tracking swan migration, it appears possible that the birds collected in Nevada may have originated in northwest Alaska (Ely et al. 1997).

There is no indication yet as to what snail intermediate host might transmit schistosomes of the genus Allobilharzia, but based on the behaviour and distribution of the swan hosts and the genetic similarity of the schistosomes from two different continents, it is suspected that the snail might be a brackish/marine species. Within the breeding range, tundra swans often feed in brackish estuarine bays and when inland, in freshwater. Suitable feeding waters must be shallow enough to use their feet to disturb aquatic vegetation and immerse the head and neck to obtain leaves, stems and tubers (Bellrose 1980) and snails can also be found in these feeding areas. Occasionally swans will consume snails (Delacour 1964), and that may suggest secondary route of transmission.

In conclusion, schistosomes were found from the tundra swan, Cygnus columbianus from North America that were morphologically and genetically determined to be Allobilharzia visceralis and were also conspecific to those recovered from C. cygnus in Iceland. A brief description of the gross pathology is reported which is very similar to the schistosomeinduced pathology reported from swans in Iceland attributed to $A$. visceralis. This extends the geographic and host range of this schistosome.
The author would like to thank Chris Nicolai (University of Nevada, Reno), Dan Rabbers (U.S. Fish and Wildlife Stillwater National Wildlife Refuge) in Nevada for their help and organisation to make this collecting possible, and the hunters at Stillwater National Wildlife Refuge Nevada for donating swan viscera and nasal tissue, and Bob Dickerman and Andy Johnson (University of New Mexico Museum of Southwestern Biology) for access to the swan from New Mexico. A special thank you to Anson Koehler (University of New Mexico) for the late, long hours of help with dissections. For helpful comments on the manuscript, thanks to Drs. Sam Loker, Michelle Steinauer and Ben Hanelt and one anonymous reviewer. I acknowledge technical support from the University of New Mexico's Molecular Biology Facility, which is supported by NIH grant number 1P20RR18754 from the IDeA program of the National Center for Research Resources. This study was supported by fund provided by the College of Arts and Sciences at UNM and NIH grant RO1 AI44913.

\section{References}

Bellrose F.C. 1980: Ducks, Geese and Swans of North America. Stackpole Books, Harrisburg, Pennsylvania, 540 pp.

BLAIR D., ISLAM K.S. 1983: The life cycle and morphology of Trichobilharzia australis $\mathrm{n}$. $\mathrm{sp}$. (Digenea: Schistosomatidae) from the nasal blood vessels of the black duck (Anas superciliosa) in Australia, with a review of the genus Trichobilharzia. Syst. Parasitol. 5: 89-117.

BOWLES J., BLAIR D., MCMANUS D.P. 1995: A molecular phylogeny of the genus Echinococcus. Parasitology 110: 317 328.

BOWLES J., MCMANUS D.P. 1993: Rapid discrimination of Echinococcus species and strains using a polymerase chain reaction-based RFLP method. Mol. Biochem. Parasitol. 57: 231240.

BRANT S.V., LOKER E.S. 2005: Can specialized pathogens colonize distantly related hosts? Schistosome evolution as a case study. PLoS Path. 1: e38.

BRANT S.V., MORGAN J.A.T., MKOJI G.M., SNYDER S.D., RAJAPAKSE J.R.P.V., LOKER E.S. 2006: An approach to revealing blood fluke life cycles, taxonomy, and diversity: provision of key reference data including DNA sequence from single life cycle stages. J. Parasitol. 92: 77-88.

CORT W.W. 1950: Studies on schistosome dermatitis XI. Status of knowledge after more than twenty years. Am. J. Hyg. 52: 251-307.

Delacour J. 1954-64: The Waterfowl of the World. Country Life, London, UK, $364 \mathrm{pp}$

DVOŘÁK J., VAŇÁČOVÁ Š., HAMPL V., FLEGR J., HORÁK P. 2002: Comparison of European Trichobilharzia species based on ITS1 and ITS2 sequences. Parasitology 124: 307-313.

ELLIS J.C., BOURNS T.K.R., RAU M.E. 1975: Migration, development, and condition of Trichobilharzia ocellata (Trematoda: Schistosomatidae) in homologous challenge infections. Can. J. Zool. 53: 1803-1811.

Ely C.R., DOUglas D.C., FOWLER A.C., BABCOCK C.A., DERKSEN D.V., TAKEKAWA J.Y. 1997: Migration behavior of tundra swans from the Yukon-Kuskokwim Delta, Alaska. Wilson Bull. 190: 679-692.

EVANS M.E., SLADEN W.J.L. 1980: A comparative analysis of the bill markings of Whistling and Bewick's swans and out-ofrange occurrences of the two taxa. Auk 97: 697-703.

GRACZYK T.K., SHIFF C.J., Sladen W.J.L., CRANField M. 1993: Attempts to control avian blood flukes in National Wildfowl Refuge in a captive system. Proc. Int. Assoc. Aquatic Anim. Med. 24: 79-83 
HorÁK P., KolÁŘovÁ L., AdEMA C.M. 2002: Biology of the schistosome genus Trichobilharzia. Adv. Parasitol. 52: 155233.

HUELSENBECK J.P., RONQUIST F. 2001: MrBayes: Bayesian inference of phylogenetic trees. Bioinformatics 17: 754-755.

JARCHO S., VAN BURKALOW A. 1952: A geographical study of "Swimmer's Itch" in the United States and Canada. Geogr. Rev. 42: 212-226.

JOHNSTON T.H. 1941: Bather's itch (schistosome dermatitis) in the Murray swamps of south Australia. Tr. R. Soc. S. Aust. 65: 276.

KEAR J. 2005: Bird Families of the World: Ducks, Geese and Swans. Oxford University Press, New York, $446 \mathrm{pp}$.

KolÁŘOVÁ L., RUdOLFOVÁ J., HAMPL V., SKÍRNISSON K. 2006: Allobilharzia visceralis gen. nov., sp. nov. (Schistosomatidae - Trematoda) from Cygnus cygnus (L.) (Anatidae). Parasitol. Int. 55: 179-186.

KolÁŘovÁ L., SKÍRNiSSON K., RudOlfovÁ J., JOUET D., LÉGER N., FERTÉ H. 2005: Avian schistosomes of the genus Trichobilharzia in final hosts in Europe. Bull. Scand. Soc. Parasitol. 14: 85-86.

KONDRATYEV A.V. 1991: The distribution and status of Bewick's swan Cygnus bewickii, Tundra swan C. columbianus and Whooper swan C. cygnus in the extreme northeast of the USSR. Wildfowl Spec. Suppl. 1: 56-61.

LEEDOM W.S., SHORT R.B. 1981: Cercaria pomaceae sp. n., a dermatitis-producing schistosome cercaria from Pomacea paludosa, the Florida apple snail. J. Parasitol. 67: 257-261.

LEVINE N.D., CLARK D.T., HANSON L.E. 1956: Encephalitis in a swan due to Dendritobilharzia sp. (Trematoda; Schistosomatidae). J. Parasitol. 42: 496-500.

LIMPERT R.J., SLADEN W.J.L., AllEN H.A. JR. 1991: Winter distribution of Tundra swans Cygnus columbianus columbi- anus breeding in Alaska and western Canadian Arctic. Wildfowl Spec. Suppl. 1: 78-83.

MORGAN J.A.T., DeJONG R.J., KaZIBWE F., MKOJI G.M., LOKER E.S. 2003: A newly identified lineage of Schistosoma. Int. J. Parasitol. 33: 977-985.

PALMER D., OSSENT P. 1984: Nasal schistosomiasis in Mute swans in Switzerland. Rev. Suisse Zool. 19: 709-715.

PosAdA D., CRANDALl K.A. 1998: Modeltest: testing the model of DNA substitution. Bioinformatics 14: 817-818.

PRITChARD M.H., KRUSE G.O.W. 1982: The Collection and Preservation of Animal Parasites. University of Nebraska Press, Lincoln, Nebraska, $141 \mathrm{pp}$.

SNYDER S.D. 2004: Phylogeny and paraphyly among tetrapod blood flukes (Digenea: Schistosomatidae and Spirorchiidae). Int. J. Parasitol. 34: 1385-1392.

SWOFFORD D.L. 2002: PAUP*: Phylogenetic Analysis Using Parsimony (*and other methods) Ver. 4. Sinauer Associates, Sunderland, MA.

SZIDAT L. 1939: Pseudobilharziella filiformis n. sp., eine neue Vogelbilharzie aus dem Hockerschwan, Cygnus olor L. Z. Parasitenkd. 10: 535-544.

VAN DEN BROEK E. 1965: Some recent cases of avian schistosomiasis and schistosome dermatitis in the Netherlands. Trop. Geogr. Med. 17: 229-235.

Webster B.L., SouthGate V.R., LitTLEWood D.T.J. 2006: A revision of the interrelationships of Schistosoma including the recently described Schistosoma guineensis. Int. J. Parasitol. 36: 947-955.

WiLSON R.B., NEW J.C., SCHOLTENS R.G. 1982: Granulomatuous encephalitis caused by schistosomiasis in swans. J. Am. Vet. Med. Assoc. 181: 1386-1387.

Received 15 November 2006

Accepted 16 April 2007 